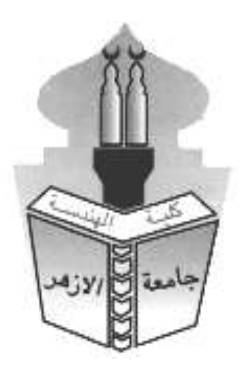

\title{
INFORMATION AND COMMUNICATION TECHNOLOGY INTERVENTION LEVELS IN VARIOUS ACTIVITIES AND ITS ROLE IN UPGRADING EGYPTIAN NEW CITIES TO SMART CITIES (CASE STUDY: TENTH OF RAMADAN CITY)
}

\author{
Mohiy Fayed Mohiy El-Ganzoury ${ }^{1, *}$, Abdel-Awal Abdel-Aziz Abd ellah Mohamed ${ }^{2}$, Mohammed M. Serag ${ }^{3}$ \\ ${ }^{1}$ Assistant Lecturer, Department of Architecture, Faculty of Engineering, Al Azhar University, Cairo, Egypt. \\ 2 Teacher, Department of Architecture, Faculty of Engineering, Al-Azhar University, Cairo, Egypt. \\ ${ }^{3}$ Professor of Architecture and Urban Planning, Faculty of Engineering, Al-Azhar University, Cairo, Egypt. \\ *Corresponding Author E-mail: Mohiy.elganzoury@gmail.com
}

\begin{abstract}
:
The information revolution has a remarkable impact on the pattern of daily life, the city and its urban centers, and the practice of various activities in the city, especially after the emergence of the Corona virus pandemic and the reliance on information and communication technology involved in these activities.

In the twenty-first century, the city relies heavily on informatics in all activities of life, and the emergence of a new type of projects called smart urban projects and their effective role in the process of urban development for those cities, Planners and urban planning policymakers and those in charge of urban development processes for existing and new cities must look to the new dimension that imposes itself by force on life and the pattern of the future development process, which is the information revolution.

The technological and informational revolution is expected to affect the design and planning of smart projects, and it is expected to have a significant impact on the city's lifestyle in the future and the urban planning of the future city.

The research deals with the impact of information and communication technology and the levels of its interference in the city planning process and various activities, And the role of smart cities in urban integration between the environment, society and the individual according to the rapid changes of technologies that occur in our world continuously.
\end{abstract}

Key words: "smart city; urban development; sustainable societies; smart city activation strategy". 


\section{مستويات تدخل تكنولوجيا المعلومات والاتصالات في الانشطة المختلفة ودورها فى الارتقاء بالمدن الجديدة المصرية الى مدن ذكية (حالة دراسية مدينة العاشر من رمضان)}

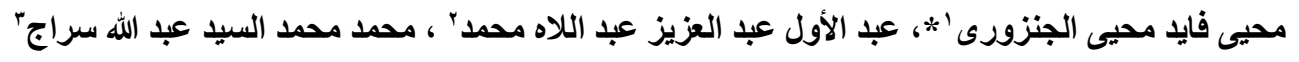

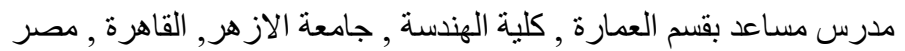

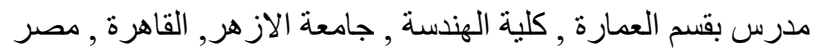

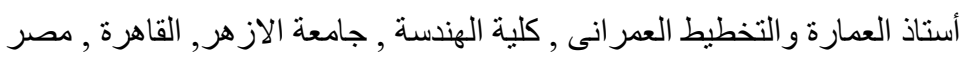

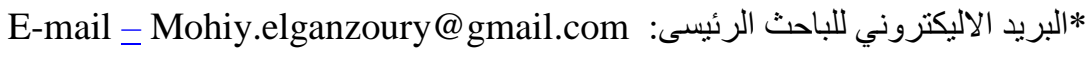

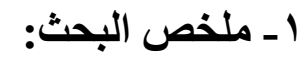

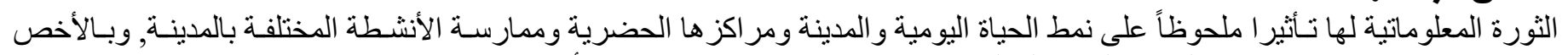

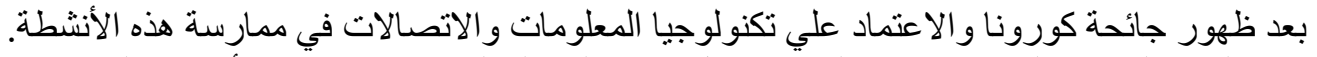

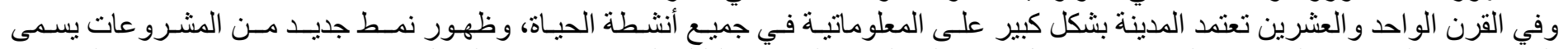

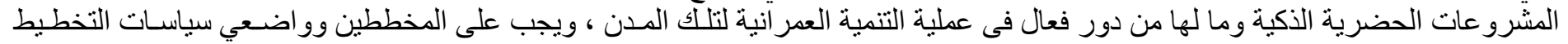

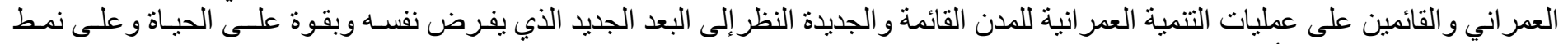

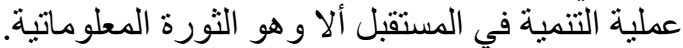

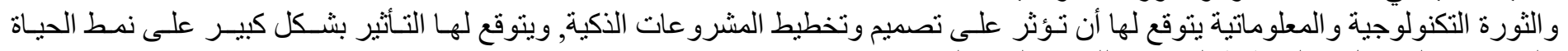

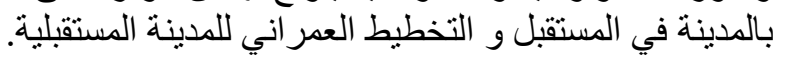

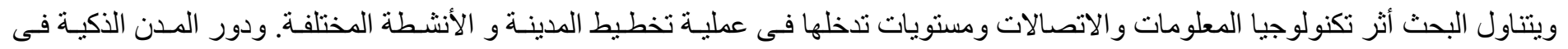

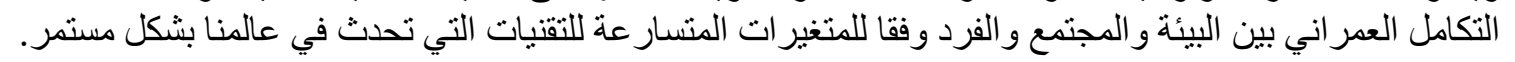

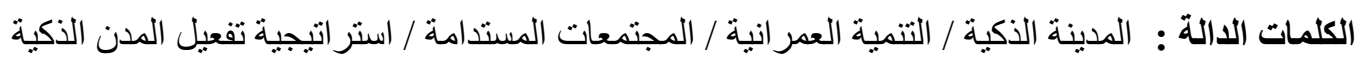

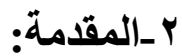

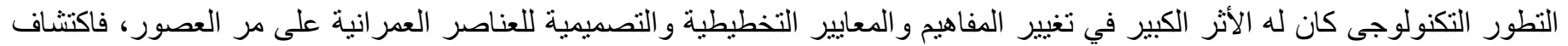

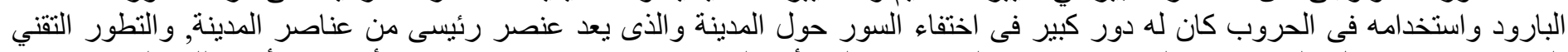

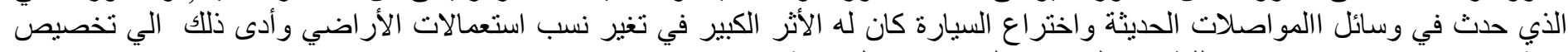

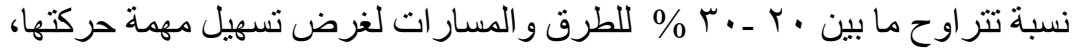

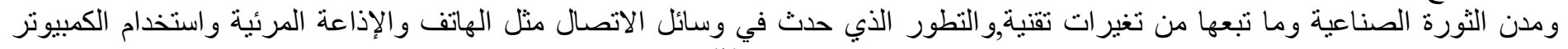

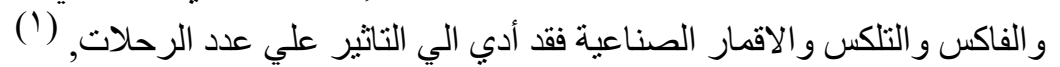

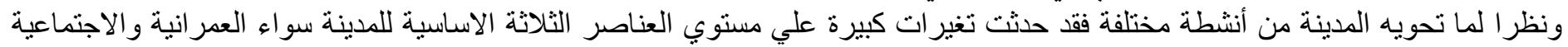
و الاقتصادية وفقا لمنطلبات هذه الانثطة الالكترونية الجديدة.

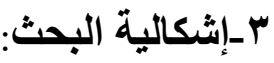

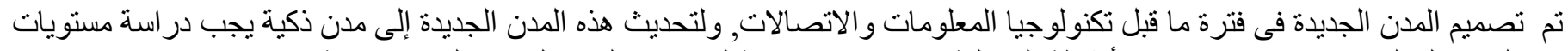
تدخل تكنولو جيا المعلومات و الاتصالات فى الأنثطة المختلفة ووضع استر اتيجية للإرتقاء بالمدن الجديدة الجيدة إلى مدن ذكية.

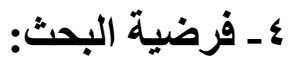

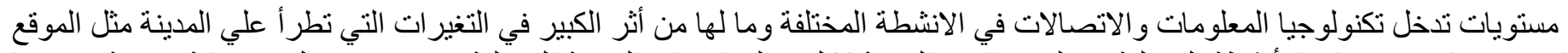

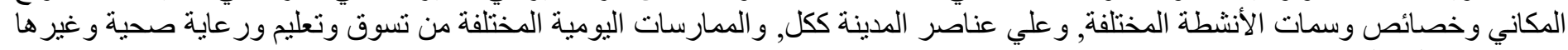
من الانشطة المختلفة. 


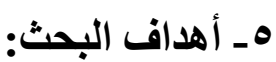 \\ بناءً على الإشكالية البحثية وفرضية الدر اسة فإن أهداف البحث كما يلى:

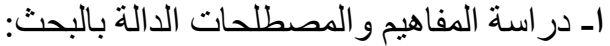

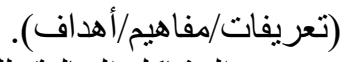

تكنولوجيا المعلومات والاتصالات/المدينة الذكية / التنمية العمر انية / المجتمعات المستدامة / استر اتيجية تفعيل المدن الذكية

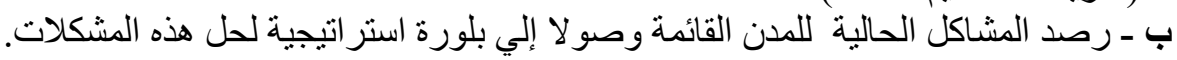

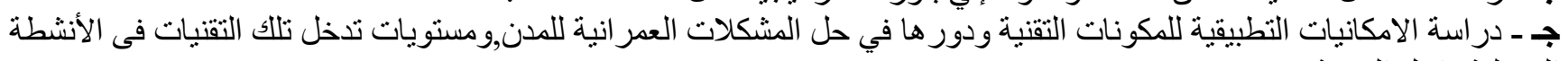

المختلفة داخل المدينة.

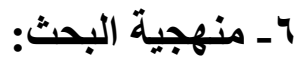

$$
\begin{aligned}
& \text { ينتع البحث المنهج النظرى و التحليلى و منهج الرصد الميدانى كأسلوب بحثى , وذلك من خلال تحديد ثلاث خطو ات كم يلى: }
\end{aligned}
$$

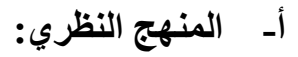

$$
\begin{aligned}
& \text { • • وذللك من خلال دراسة المفاهيم العامة للبحث. }
\end{aligned}
$$

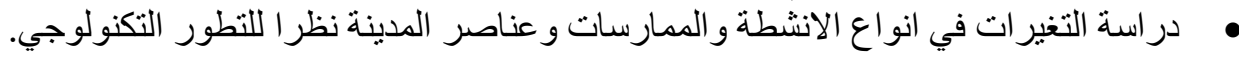

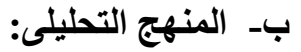

• • دراسة وتحليل الأنثطة المختلفة بالمدينة محل الدر اسة ومدى تأثر ها بتكنولوجيا المعلومات و الاتصالات من خلال عناصر الدينة.

• من خلال الدراسة النظرية والتحليلية لنسب تدخل تكنولوجيا المعلومات و الاتصالات فى الأنشطة و الخدمات بالمدينة محل الدراسة. • • وضع استر اتيجية للإرتقاء بالمدن الجديدة القائمة إلى مدن ذكية.

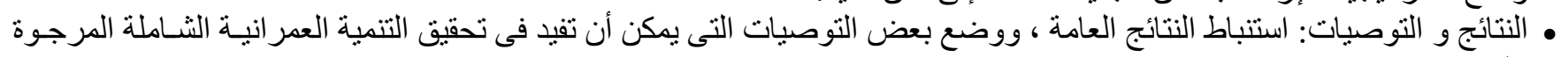

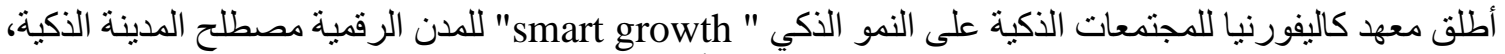

أى التتمية التي تعتمد على تقنية الاتصالات و المعلومات، باعتبار أن المجتمع الذكي هو المجتمع الذي ييذل جهد لاستخدام تقنيات المعلومات لتنغيير

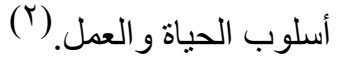

و المجتمعات المستدامة هى " مجتمعات تثمل على كافة عناصر المدينة من سكن و عمل حالى و مستقبلى ، فهي مجتمعات مستدامة نظر الإلى الكونها

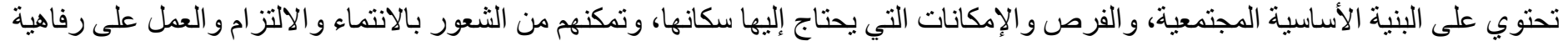

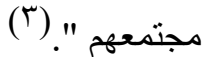

و التنمية المستدامة هى " إستر اتيجية تسعى بو اسطتها المجتمعات الإنسانية لتطوير سياستها التتموية (الإقتصادية والإجتماعية و الثقافية والسياسية

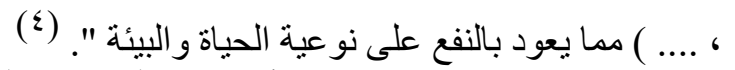

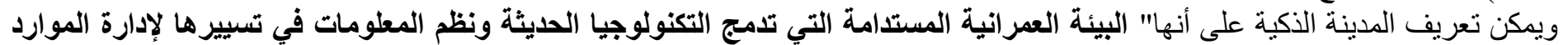

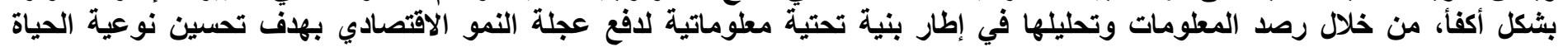

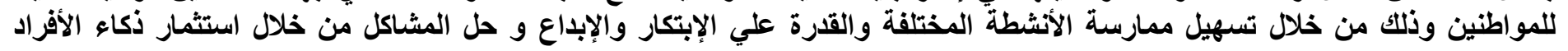

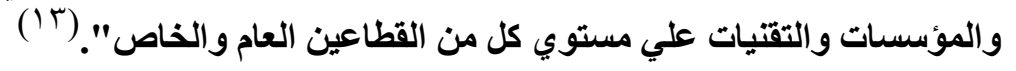

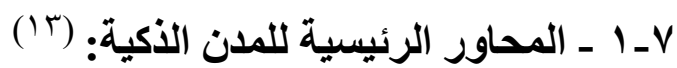

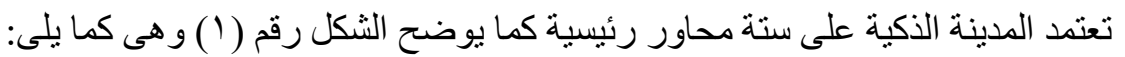

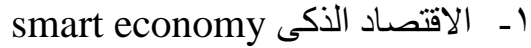

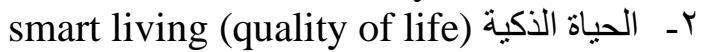
Smart environment ك- البيئة الذكية

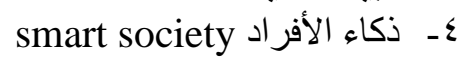

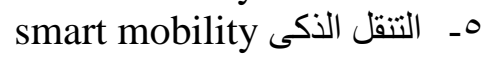

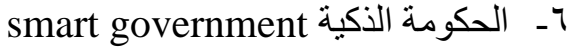




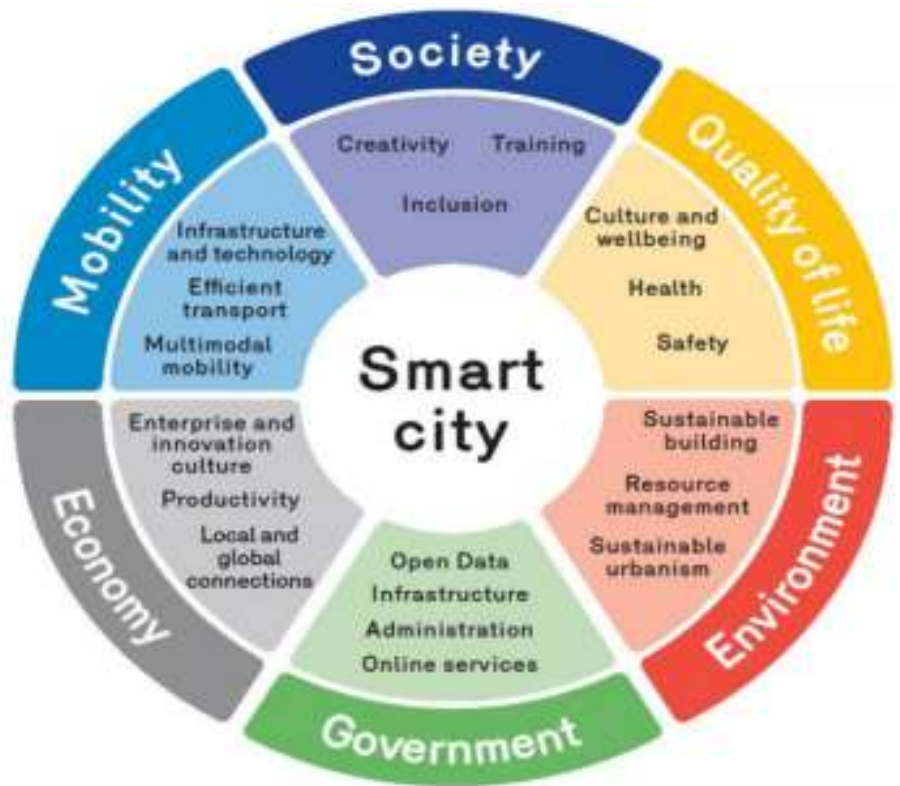

المحاور الستة الرئيسية للمدينة الذكية(0)

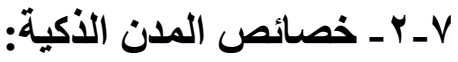

تتميز المدن الذكية بالخصائص التالية كما يوضح الثكل رقم (r). خصانص المدن الفنية

\begin{tabular}{|c|c|c|c|c|}
\hline ألمبالزد المطبيجية & إكيرا المولع & الفكابل العبرافى & الاصشياد المستغيلى & 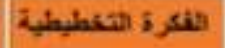 \\
\hline 25 & 25 & 22 & 25 & 25 \\
\hline 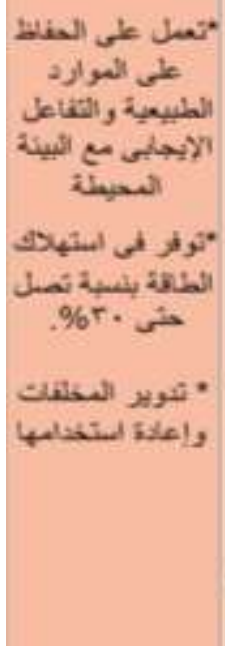 & 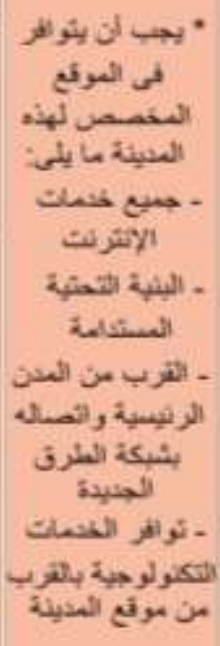 & 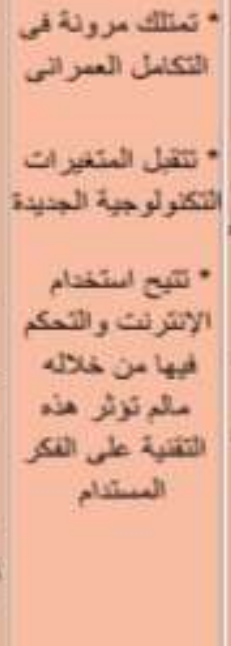 & 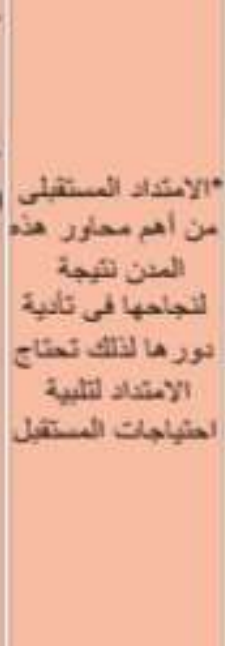 & 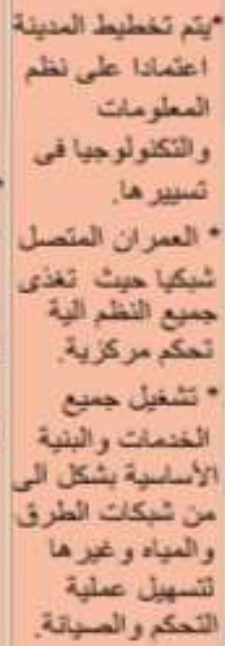 \\
\hline
\end{tabular}

شكل رقم (ץ) : خصائص المدن الذكية (بتصرف الباحث)

^ـ التغييرات التي تطرأ على المدينة في عصر المعلومات (ج)

يجب معرفة مجالات التأثثر الأولى لهذه التكنولوجيا والتي ظهرت على الأنشطة المختلفة. ويمكن أن نحددها كما يلي: 
اـ التغيير في الموقع المكاني للأنشطة الإنسانية: تكنولوجيا المعلومات والاتصالات وفرت إمكانية تحرير الأنشطة الإنسانية دون المحددات

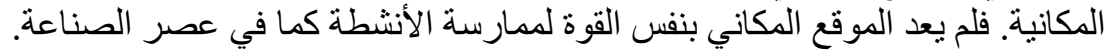

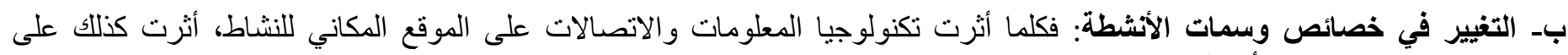
خصائص وسمات هذه في الأنشطة.

\section{جـ التغيير في وسائل وآليات تنظيم وإدارة هذه الأنيطة، فأنثطة:}

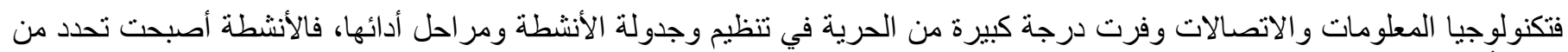

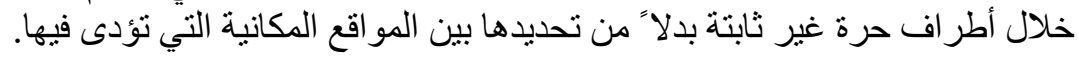

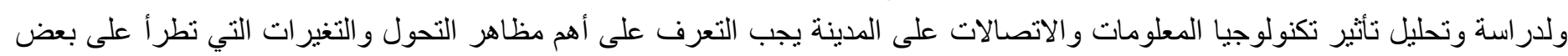
عناصر المدينة.

1ـ ا ـ أثز الثورة التكنولوجية على عناصر المدينة الأساسية (المسكن - موقع العمل):

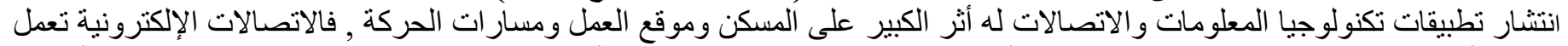

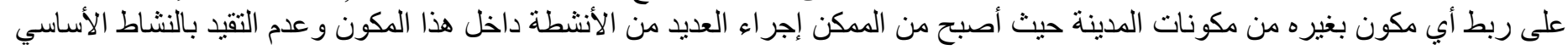

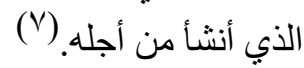

فالمسكن و هو غاية الإنسان الأولى وأهم مكونات المدينة وذلك لأنه يمثل المأوى وفيه يمكن ممارسة غالبية الأنشطة الاجتماعية ، فالمنزل هو

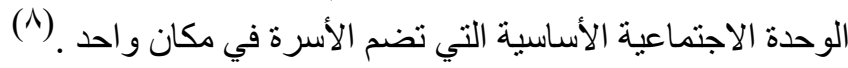

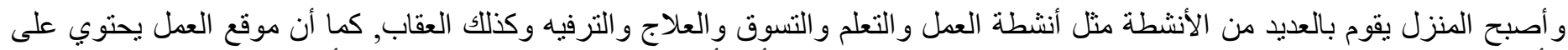

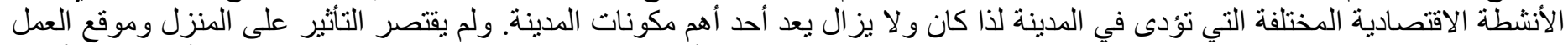

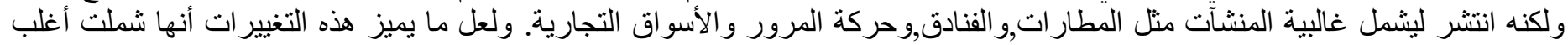

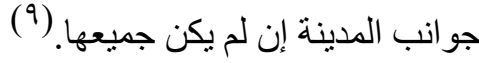

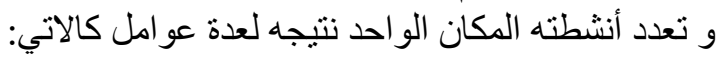

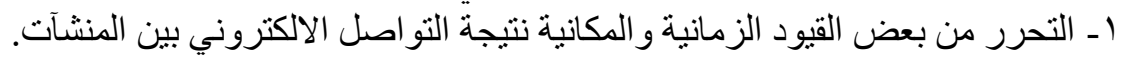
r ـ تغير رؤية المستعمل تجاه المكان, فلم يعد المستعمل يرى أن المنزل هو مكان الر احة فقط بل بدأ ير اه كفر اغ شامل لممارسة الأنشطة الحياتية كـ تأثر الهيكل الاجتماعي للمدينة حيث تغيرت العلاقات الاجتماعية الإنسانية بين المستعملين كما تأثر التكوين الاجتماعي لهم.

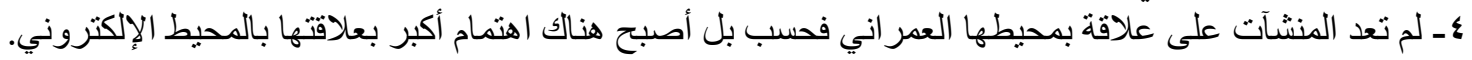

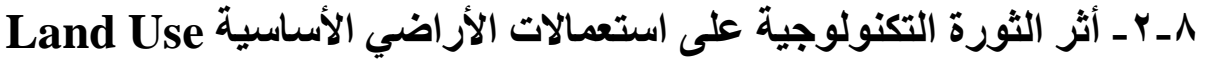

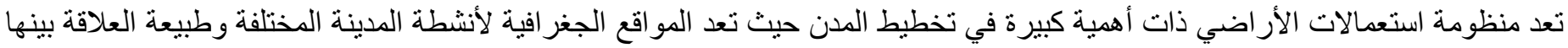

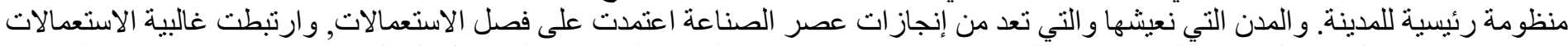

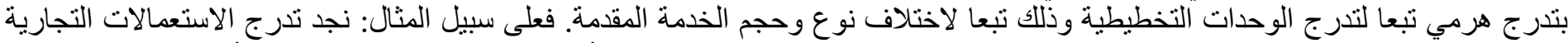

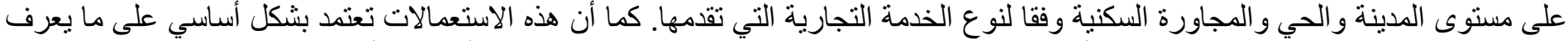
بمسافة السير (walking distance) و هي أقصى مسافة يمكن انتقالها للوصول إلى الخى الخدمة. و يمكن أن نحدد أربع احتمالات مختلفة لاستعمالات الأر اضي هي:

$$
\begin{aligned}
& \text { • استعمالات أراضي يتقلص ورجو دها تدريجيا. }
\end{aligned}
$$

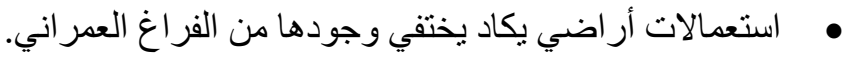

$$
\begin{aligned}
& \text { • • • • • • • • }
\end{aligned}
$$

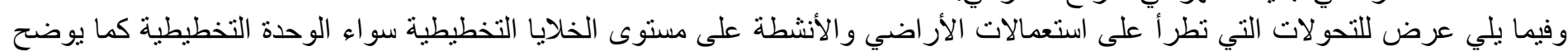

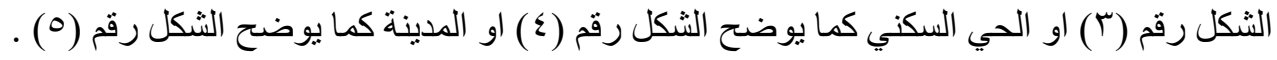


مستويات تدخل تكنولوجيا المعلومات والاتصالات في الانثطة المختلفة ودور ها فى الارتقاء بالمدن الجديدة الدصرية الى مدن ذكية (حالة دراسية مدينة العانشر من رمضان)

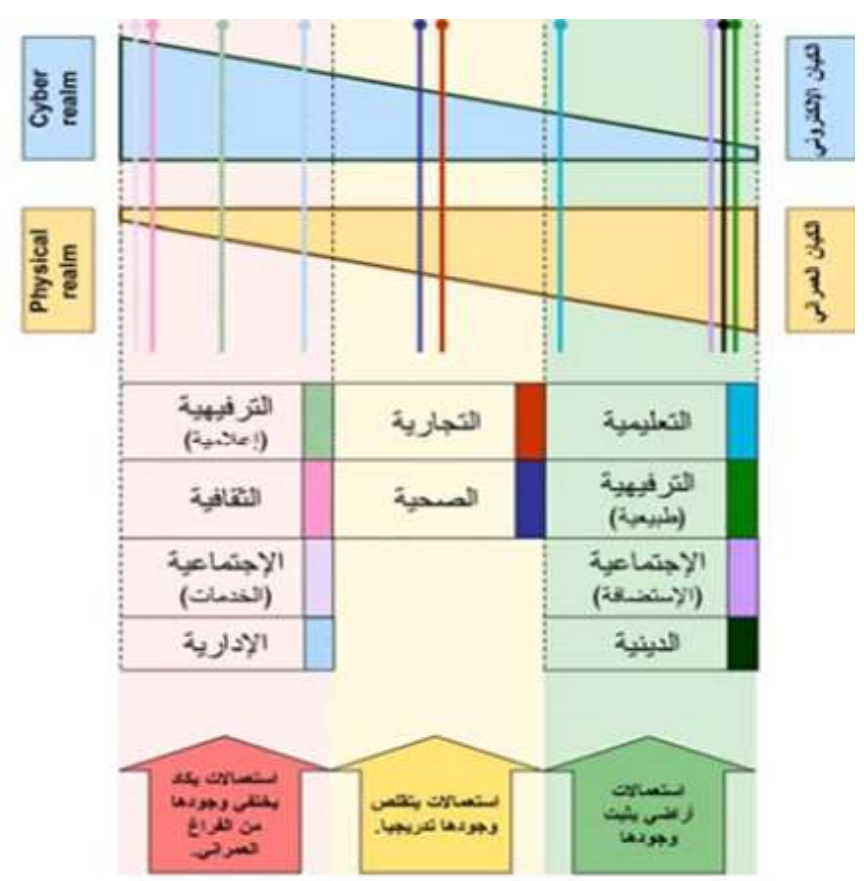

شكل رقم (؛) : أثر التكنولوجيا الحديثة علي الأنثطة المختلفة علي مستوي

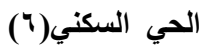

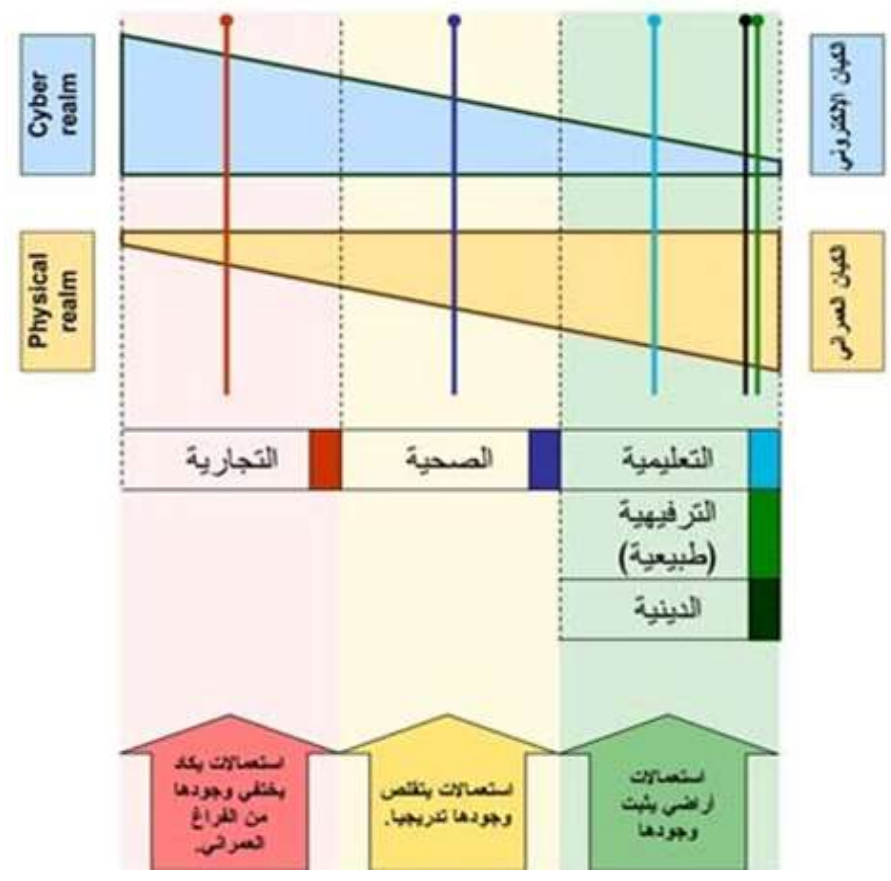

شكل رقم (r): أثر التكنولوجيا الحليثة علي الأنثطة المختلفة علي مستوي الوحدة التخطيطية (†) الأنطة

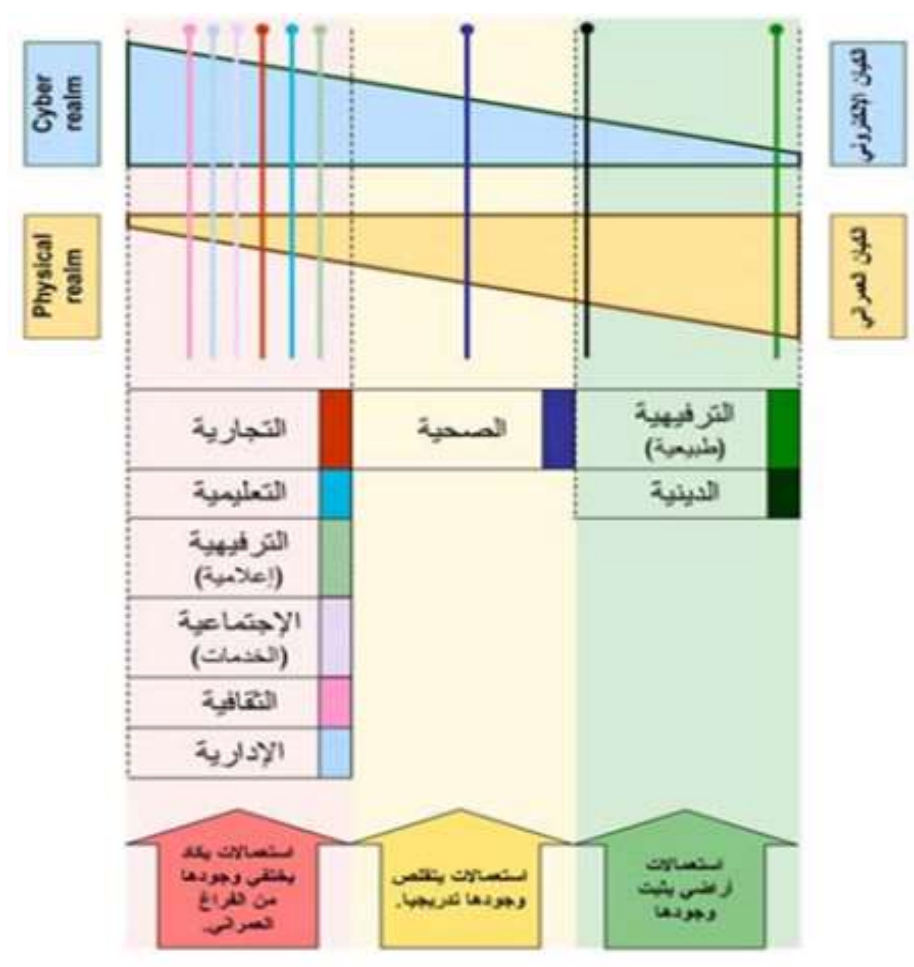

شكل رقم (•): أثر التكنولوجيا الحديثة علي الأنثطة المختلفة علي مستوي

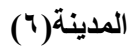


1ــــ أثر الثورة التكنولوجية على الأنشطة المختلفة بالمدينة (ج)

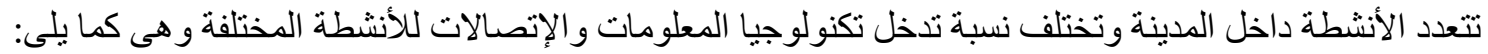

اـ الانثطة التعليمية Educational activities : تتمثل من خلال التعلم عن بعد وتنقسم الي التعليم الالز امي كالابتدائي و الاعدادي و الثانوي ويتوفر على مستوى كل من الوحدة التخطيطية و الحي السكني و التعليم العالي و المستمر ونتتوفر الخدمة على مستوى المدينة أو المحافظة أو الإقليم الحيوى وتلحظ تطور ا كبير ا. الحئ.

والـ الانثطة الصحية Health Activities : يتنامى دور الخدمة الطبية على مستوى الخلايا التخطيطية حيث بشمل خدمات المنابعة الطبية

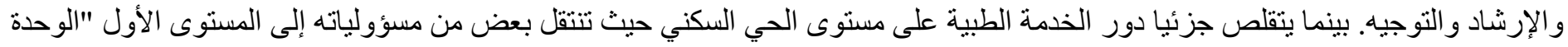

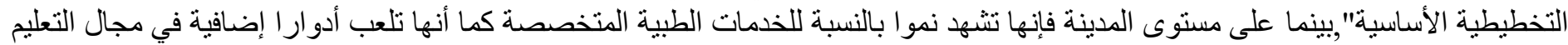

بـ الأنثطة الثقافية Cultural activities : وهى من أكثر الاستعمالات التي تثهـ تطورا وتحو لا نحو المعلوماتية، فأنشطة هذا الاستعمال

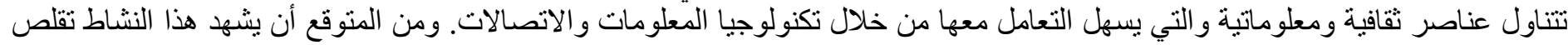
تدريجي في الكيان العمر اني ولكن فى مقابل ازدهار في الكيان الالكترونى.

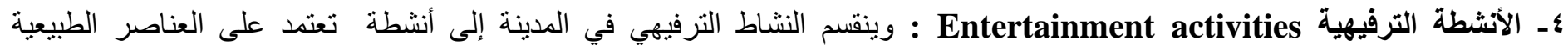

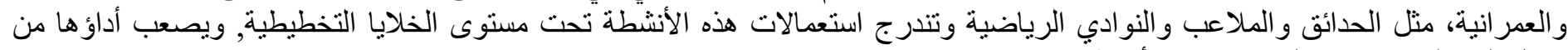
خلال التكنولوجيا ويستحيل في بعض الأنشطة.

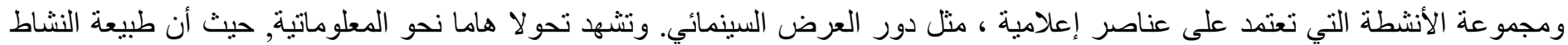

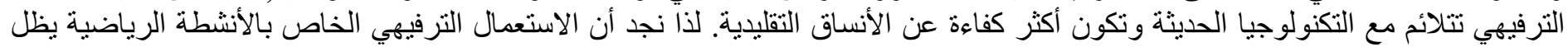

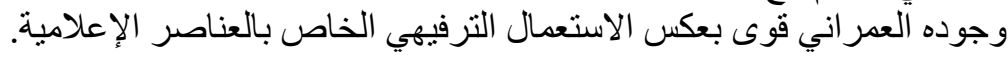

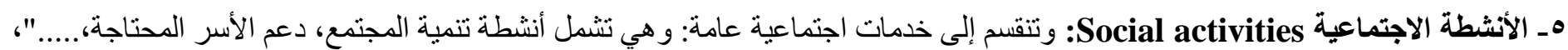

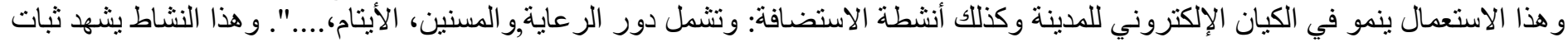
وجوده في الكيان العمر اني . الكي.

؟- الانثطة التجارية Commercial activities

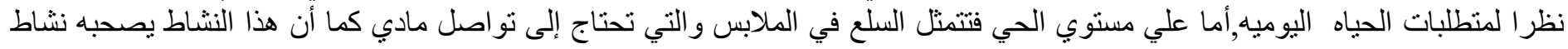

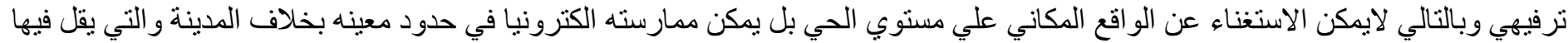

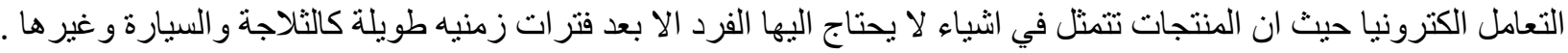

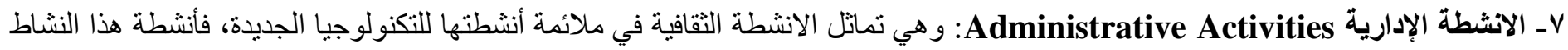

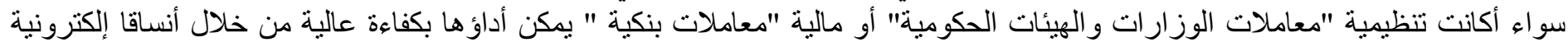

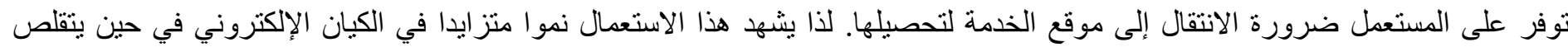
جزئيا وجوده في الكيان العمر اني وتتلاشي ضرورة اللى مورة التجاور مكانيا معه من أجل تحصيل الخدمات التي يقدمها.

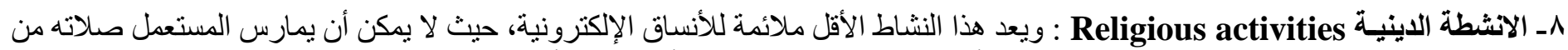

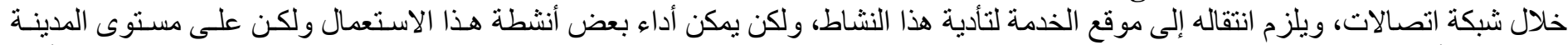

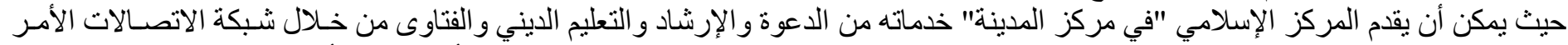

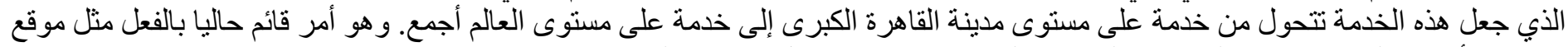
مشيخة الأزهر على الإنترنت والذي يقدا الخدمات السابق ذكر ها من خلال موقعه الإلكتروني.

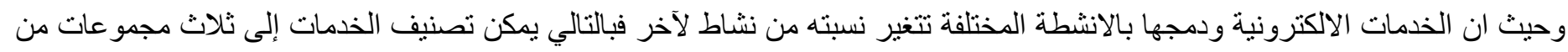

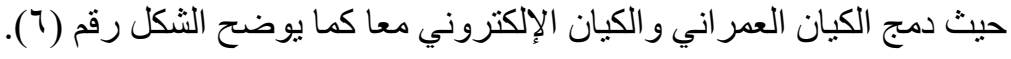




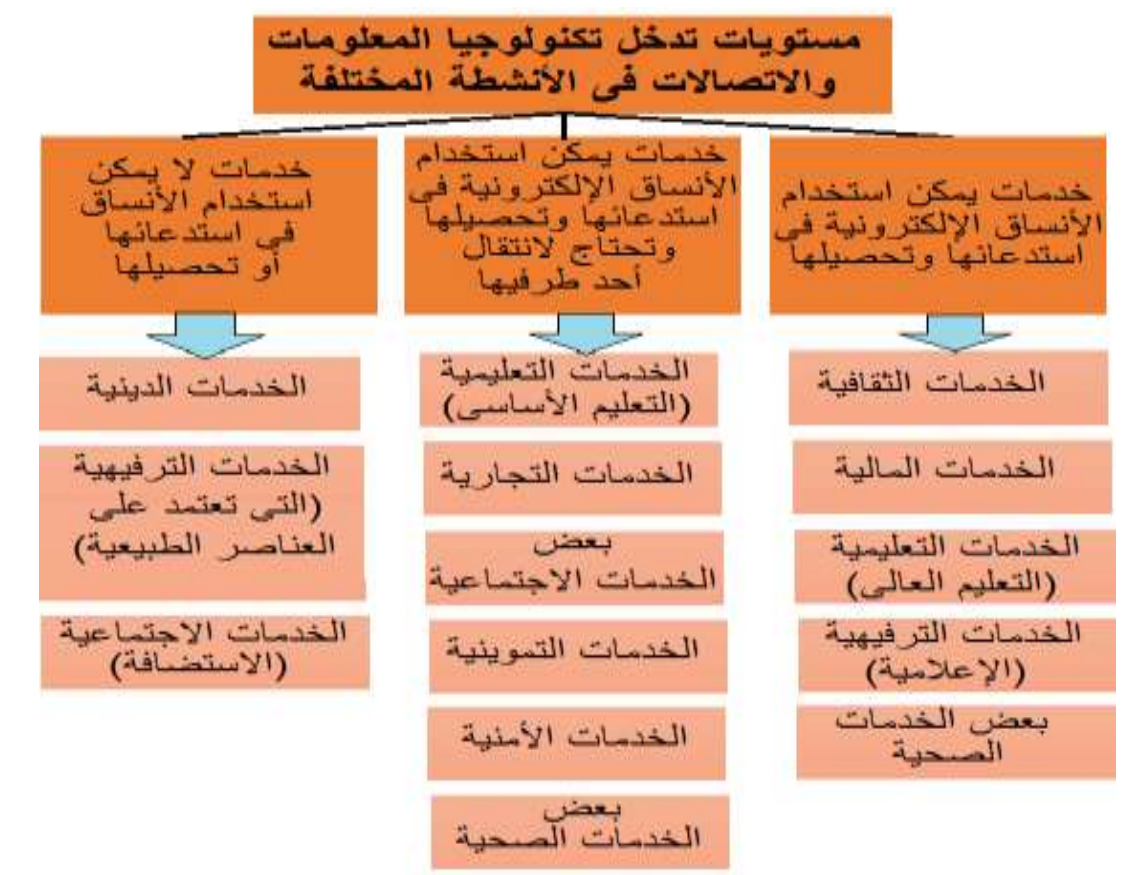

شكل رقم (ך): مستويات تلخل تكنولوجيا المعلومات والاتصالات بالأنثطة المختلفة (بتصرف الباحث)

\section{9 ـ المدينة محل الاراسة مدينة العاشر من رمضان}

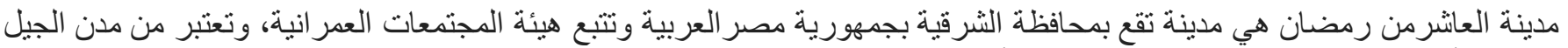

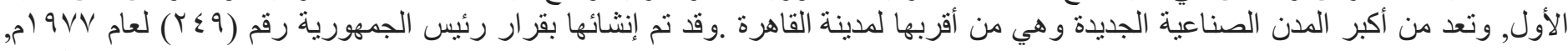

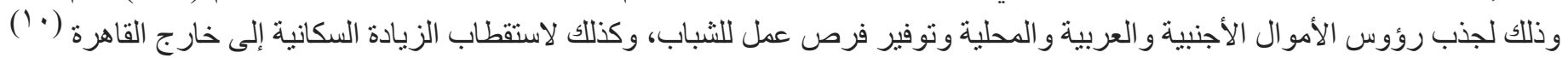

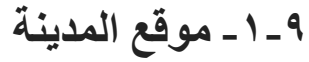

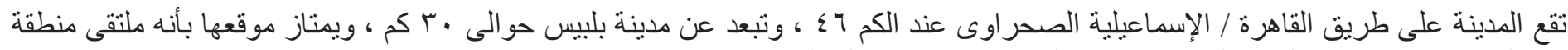

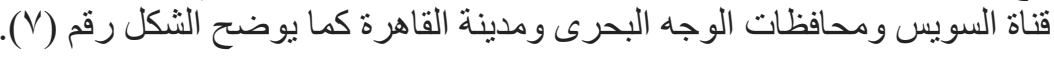

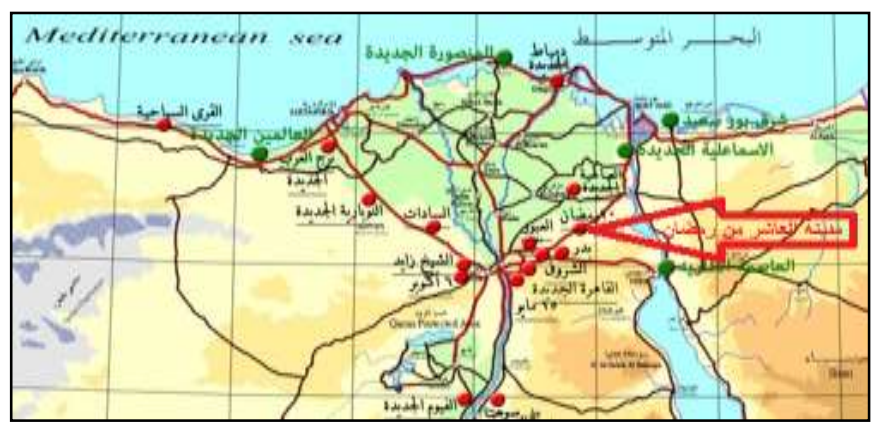

شكل رقم (v): موقع مدينة العاشر من رمضان بجمهورية مصر العربية (·') 


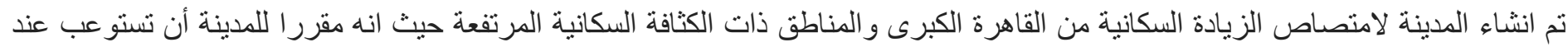

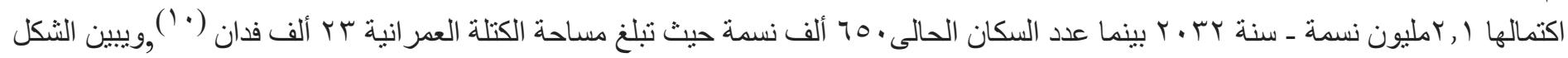

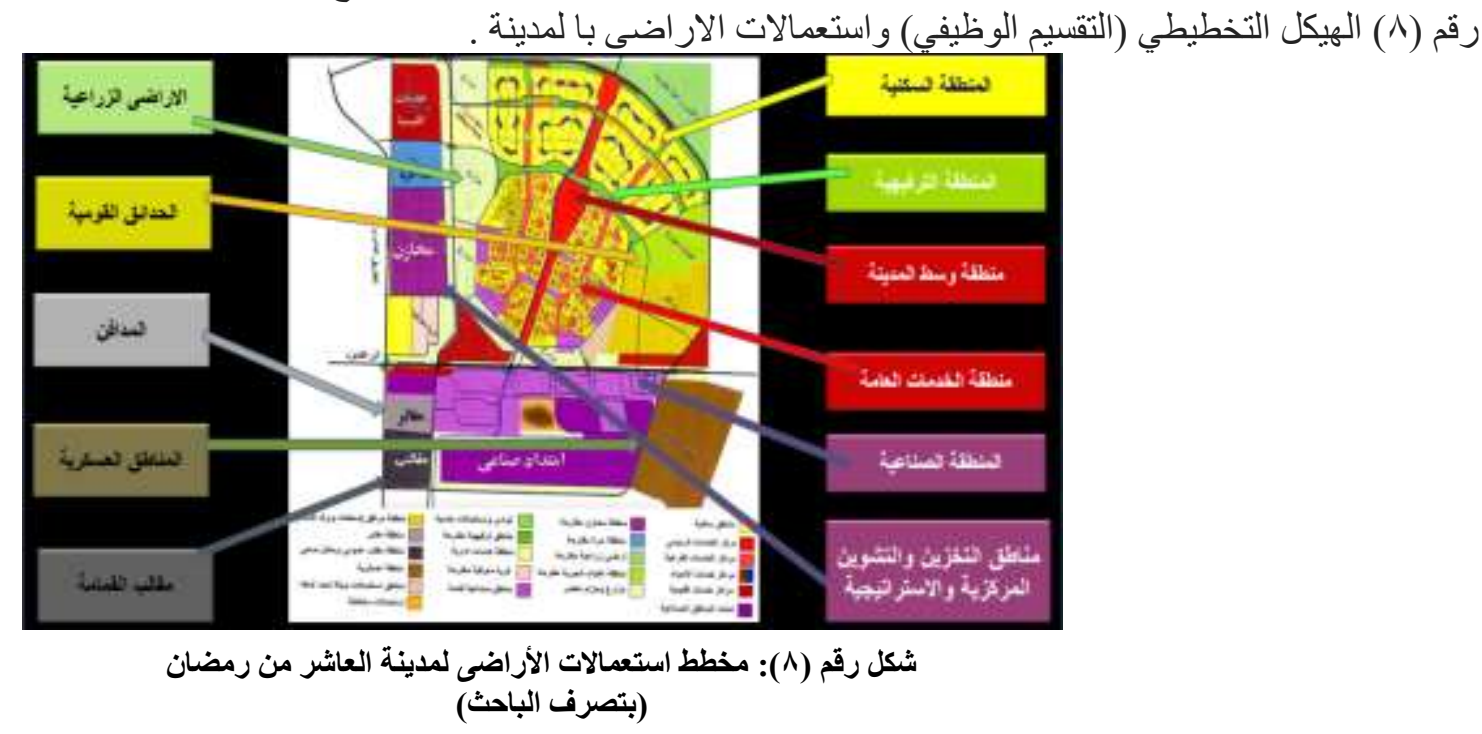

وتعاني المدينة من بعض أوجه القصور، مما أدى إلى ضعف المدينة في اجتذاب العدد المستهدف من السكان وتثير الدراسات إلى أهم هذه الأوجه كما يلي:

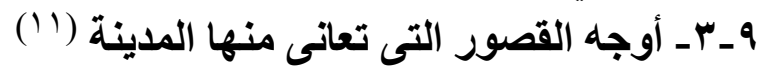

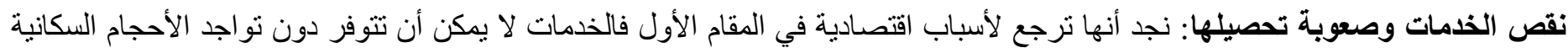

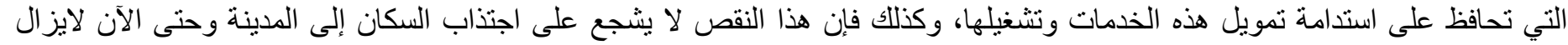

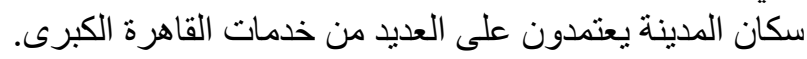

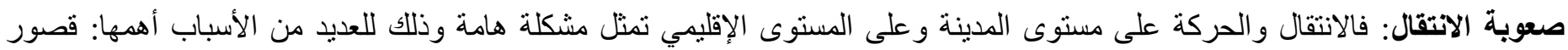

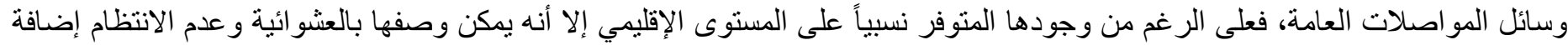

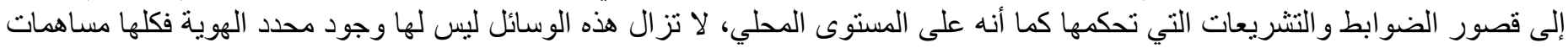

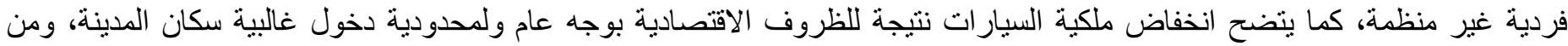

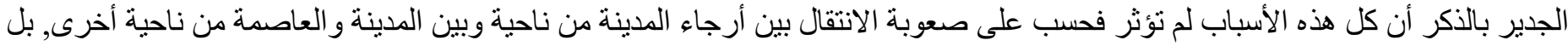

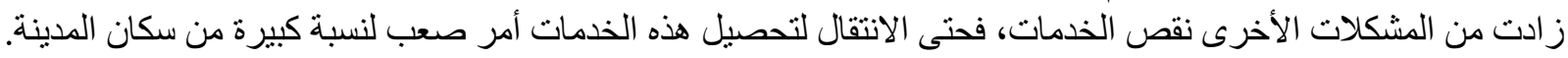
ارتفاع تكاليف المعيشة: وهو الناتج عن المشكلتين السابقتين و هما نقص الخدمات وصعوبة الاتهن الانتقال.

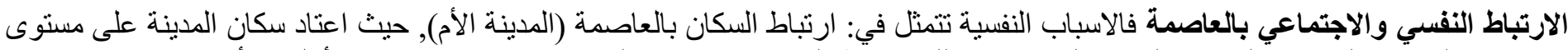

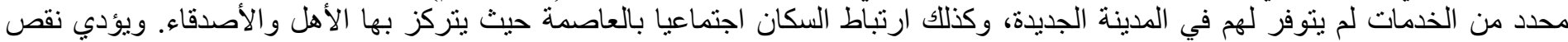

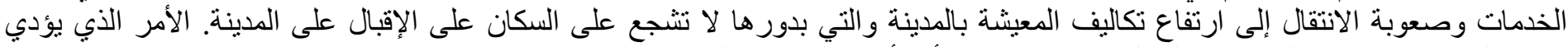

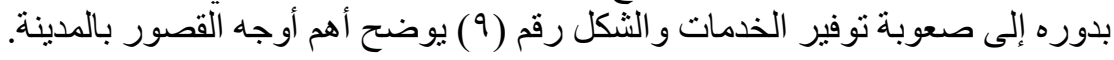




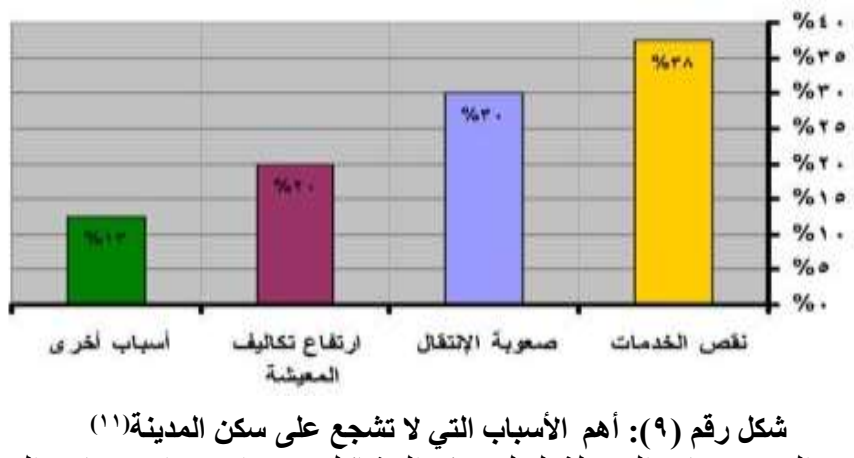

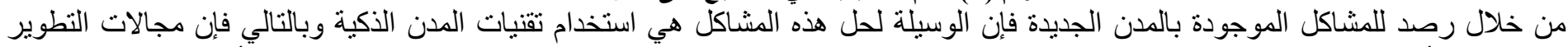
تكون حسب أولويات حل المشاكل القائمة بالمدينة و المتمثلة في نقص الخدمات وصعوبة الإنتقال مما ينتج عنه ظهور مشاكل أخري وارتفان فالناع تكاليف

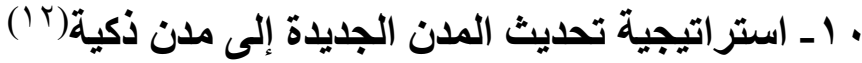

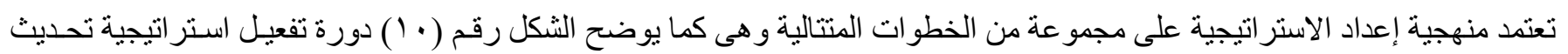

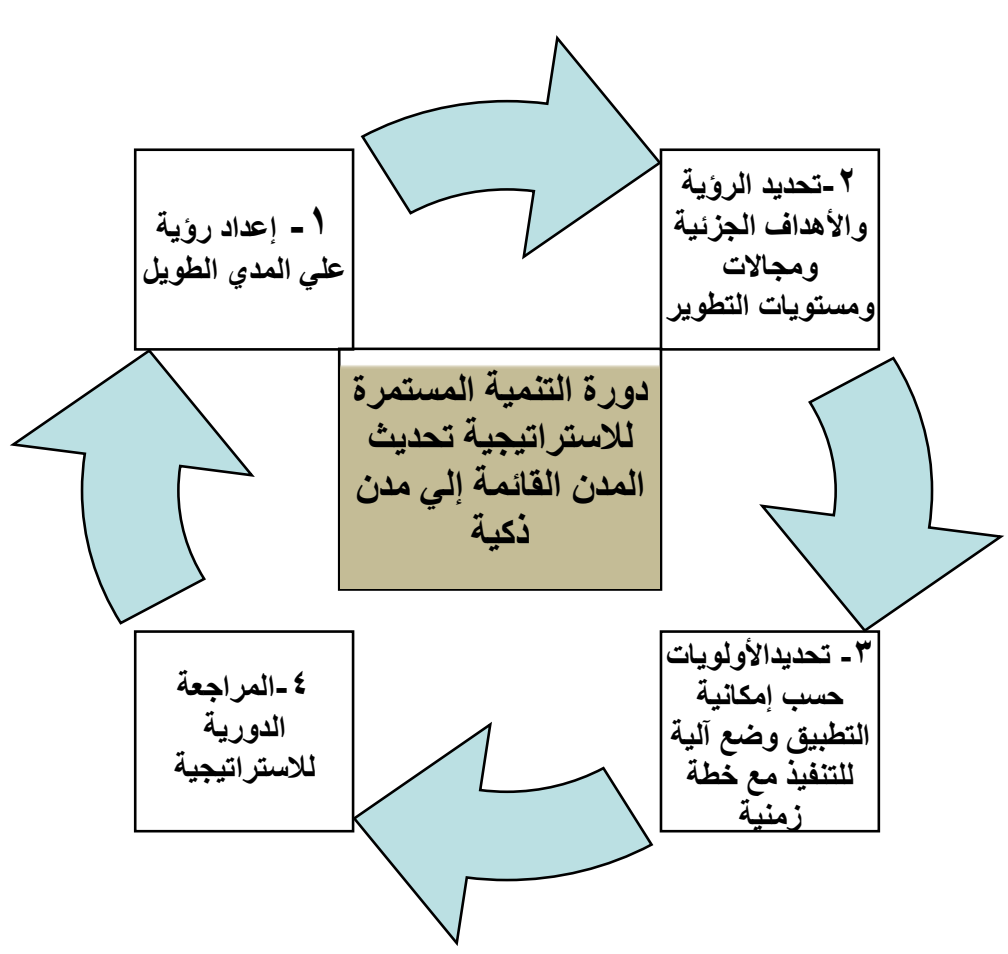

المدن القائمة إلى مدن ذكية.

شكل رقم (• (1): استراتيجية تحديث المدن القائمة إلي مدن ذكية (بتصرف الباحث)

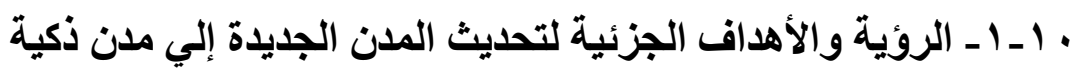

و تتمثل الأهداف الجزئية للتحديث اعتمادا علي حل المشاكل سابقة الذكر الموجودة بالمدن الجديدة, وفيما يلي الأهداف الرئيسية لتحويل المدن الجديدة إلى مدن ذكبة وهي كالتالي:

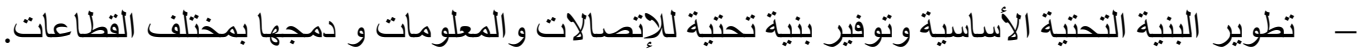

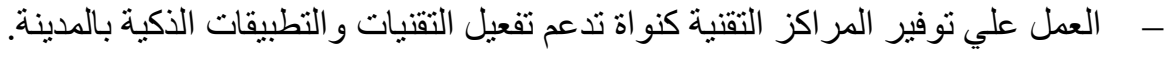
- - - الترويج للاستثمار وتوفير سبل لتقنيات التجارة الإلكترونية 
- - ـوفير خدمات إلكترونية ذكية تعمل على حل المشـاكل بالمدينـة وتـوفير بيئـة ذكيـة مـع ضـمان توفير هذه الخدمات لكافـة سكان المدينـة بمختلف الطبقات. - - العمل علي إنشاء بيئة خضر اء ومستدامة واعتماد أنظمة جديدة للطاقة النظيفة واستخدام أنظمة صديقة للبيئة.

• ـ ـ - - مجالات التطوير الأكية للتطبيقات والخدمات بالمدن الجديدة

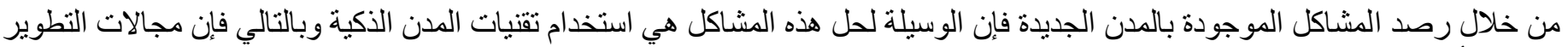

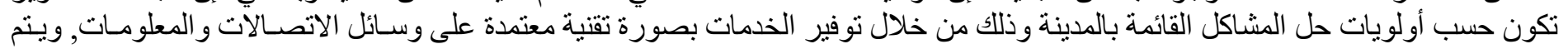

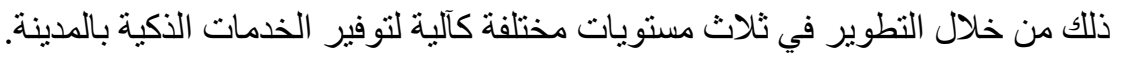

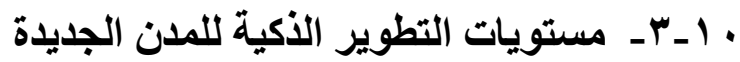
وتتمثل المستويات الأربعة للتطوير الذكي بالمدن الجديدة كالآتي:

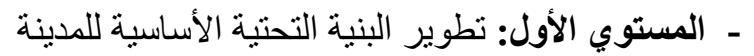

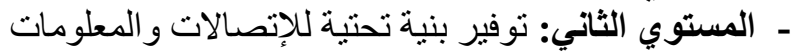
ـ - المستوي الثالث: تطوير الخدمات والأنشطة المختلفة بالمدينة.

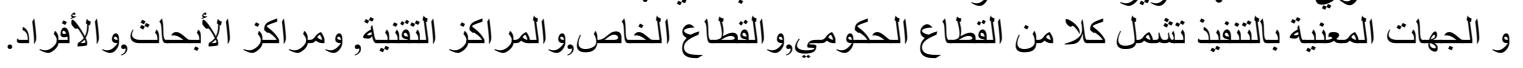

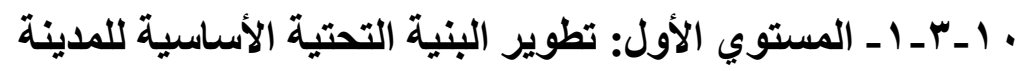
يجب تطوير البنية التحتية الأساسية للمدينة وفقا لمعاير الأستدامة كخطوة أولية, و التطوير علي مستوي البنية التحتية الأساسية يكون من خلال : تطوير شبكات البنية التحتية : اعتماد أنفاق الخدمة لمد الثبكات بالمدينة بدلا من دفن الخطوط في الأرض وحدوث مشـاكل في رصد و إصـالاح

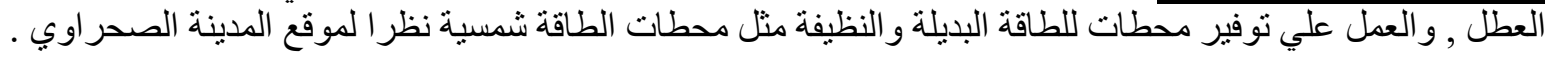

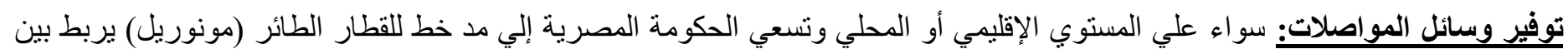

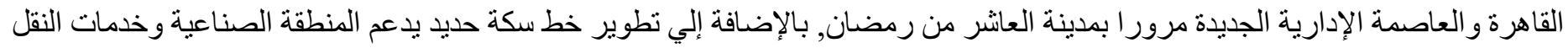

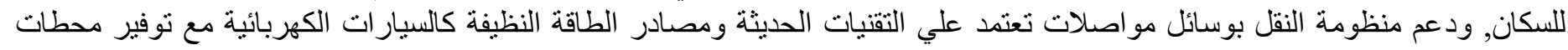
الثنحن و الترويج لدعم هذه الدنظومة الحديثة في النقل و المو أصلات.

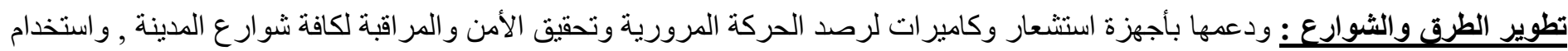

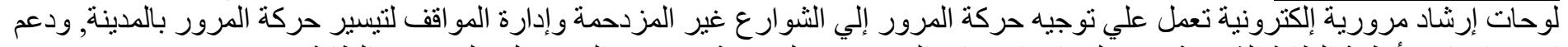

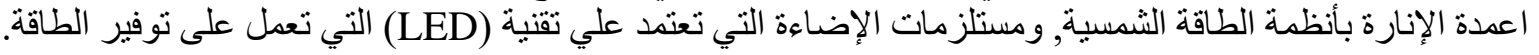

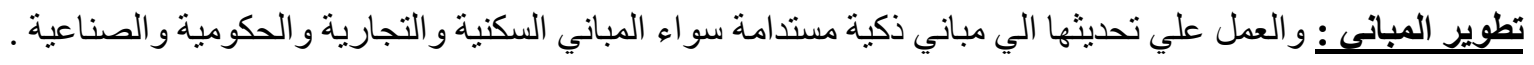
و الثكل رقم(1 (1) يوضح أنفاق الخدمة وأجزة الاستثعار فى تطوير شيكات البنية التحتية

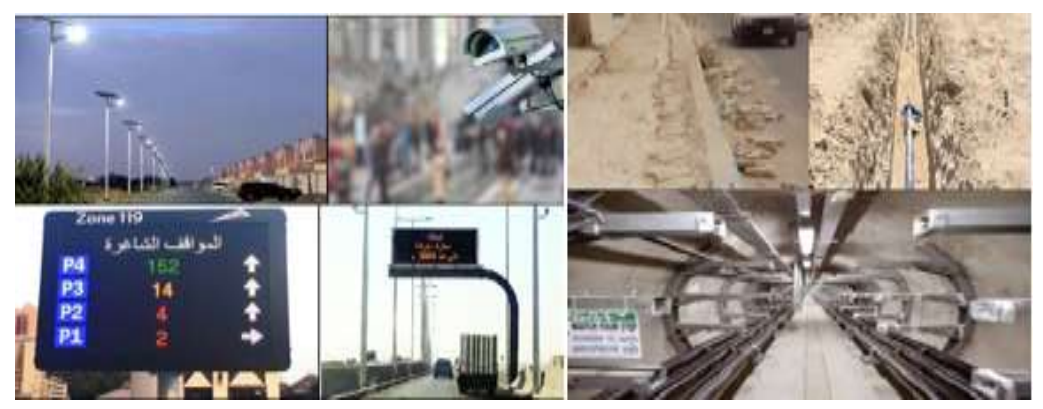

شكل رقم (1 1 ): اعتماد أنفاق الخدمة وأجزةة الاستثعار فى تطوير شيكات البنية التحتية (بتصرف الباحث)

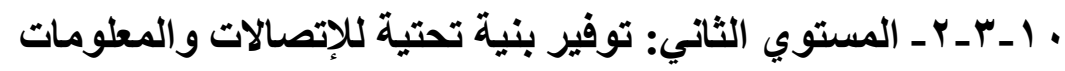


إن البنية التحتية للاتصـالات و المعلومات تعد الركيزة الأساسية للمدينة الذكية , حيث يمكن من خلالها توفير التطبيقات و الخدمات بصسورة تقنيـة

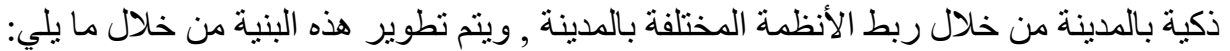

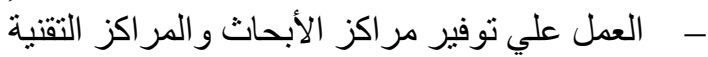

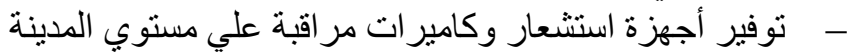

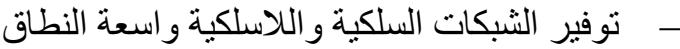

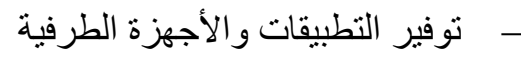

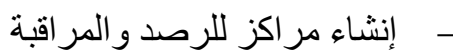

حيث يمكن من خلالها التحكم في الأنظمة المختلفة بالمدينة وتوفير الدعم للسكان كما يوضح الثكل رقم (Y I ).

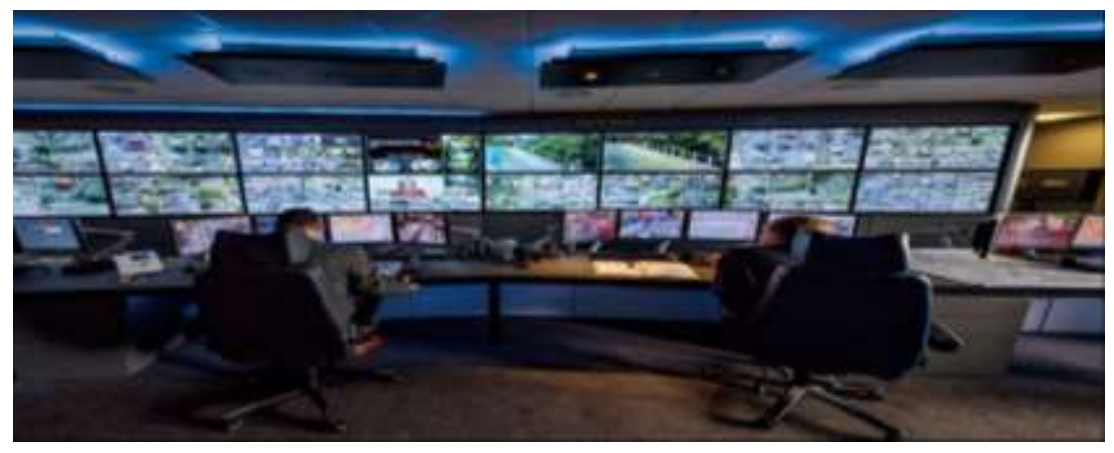

شكل رقم (r ا ): أحد مراكز الرصد والمراقبة بالمدن الذكية

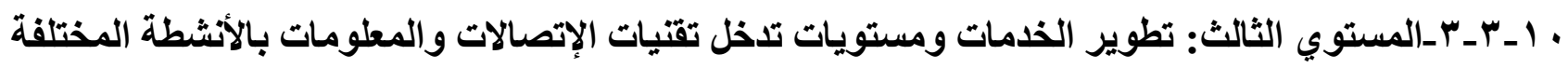

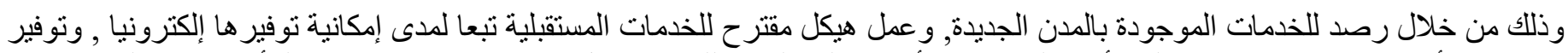

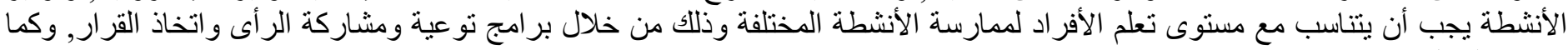

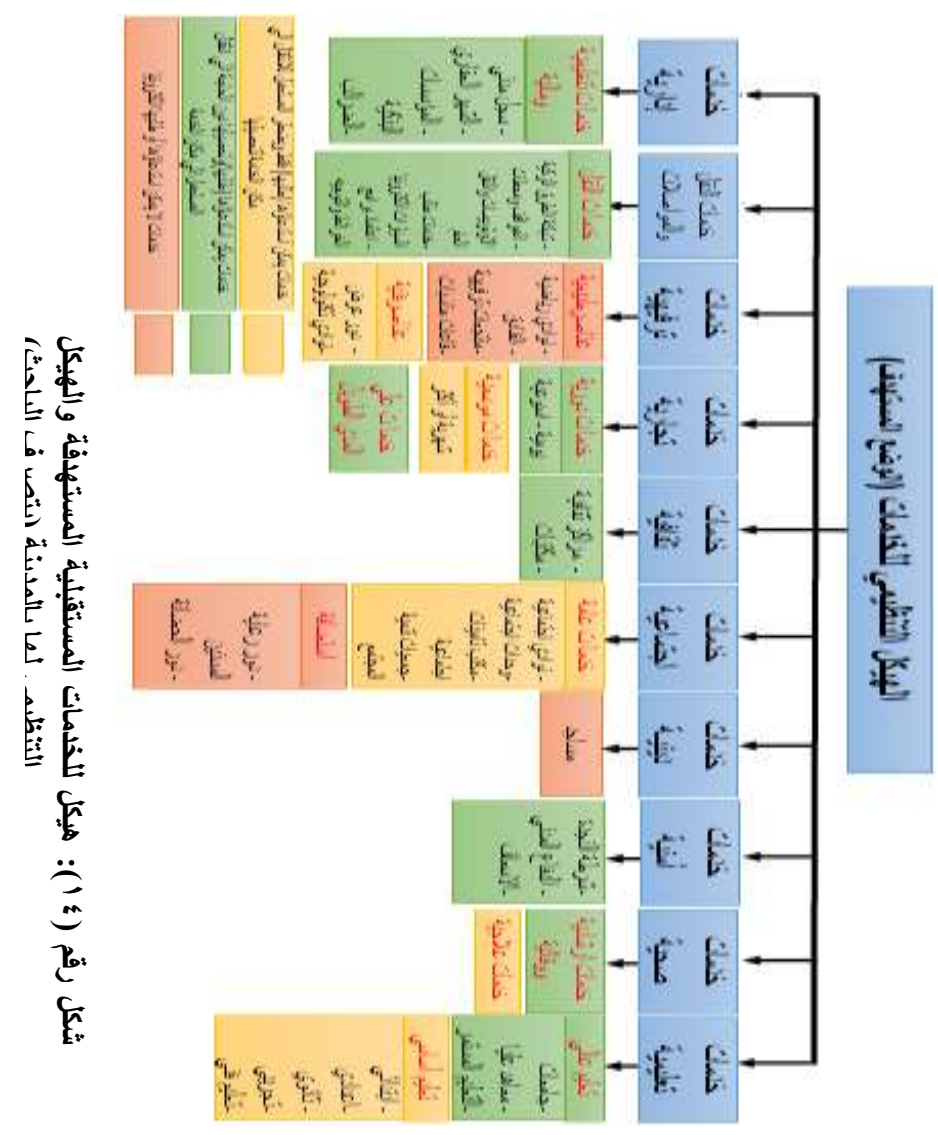

يوضح الشكل رقم (1 ا ) ( ) ( ). 
مستويات تدخل تكنولوجيا المعلومات و الاتصالات في الانثطة المختلفة ودور ها فى الارتقاء بالمدن الجديدة المصرية الى مدن ذكية (حالة دراسية مدينة العاشر من رمضان)

• 1 ـ ـ ـ الخطة الزمنية لتحديث المدن الجديدة إلي مدن ذكية في حالة وجود مدينة جديدة مكونة من ستة أحياء وكل حي مكون من ستة مجاورات كما بوضهح الثكل رقيه رقم (10).

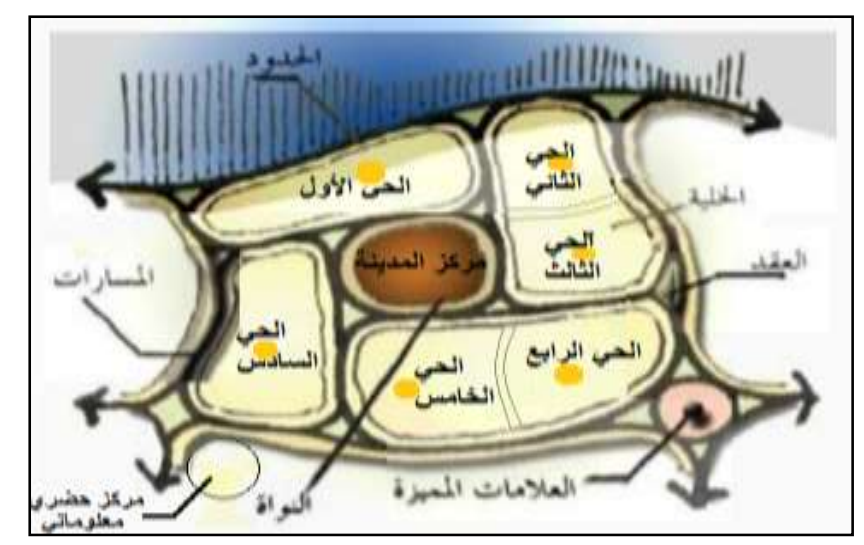

شكل رقم (0 1 ): اسكتش يوضح مدينة مكونة من ستة أحياء (بتصرف الباحث)

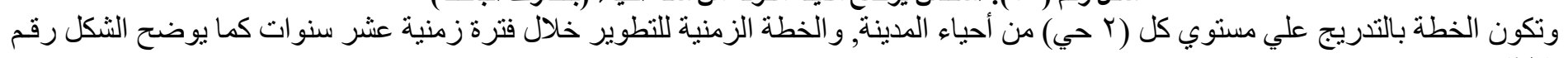


مستويات تدخل تكنولوجيا المعلومات والاتصالات في الانثطة المختلفة ودور ها فى الارتقاء بالمدن الجديدة المصرية الى مدن ذكية (حالة دراسية مدينة العانشر من رمضانة)

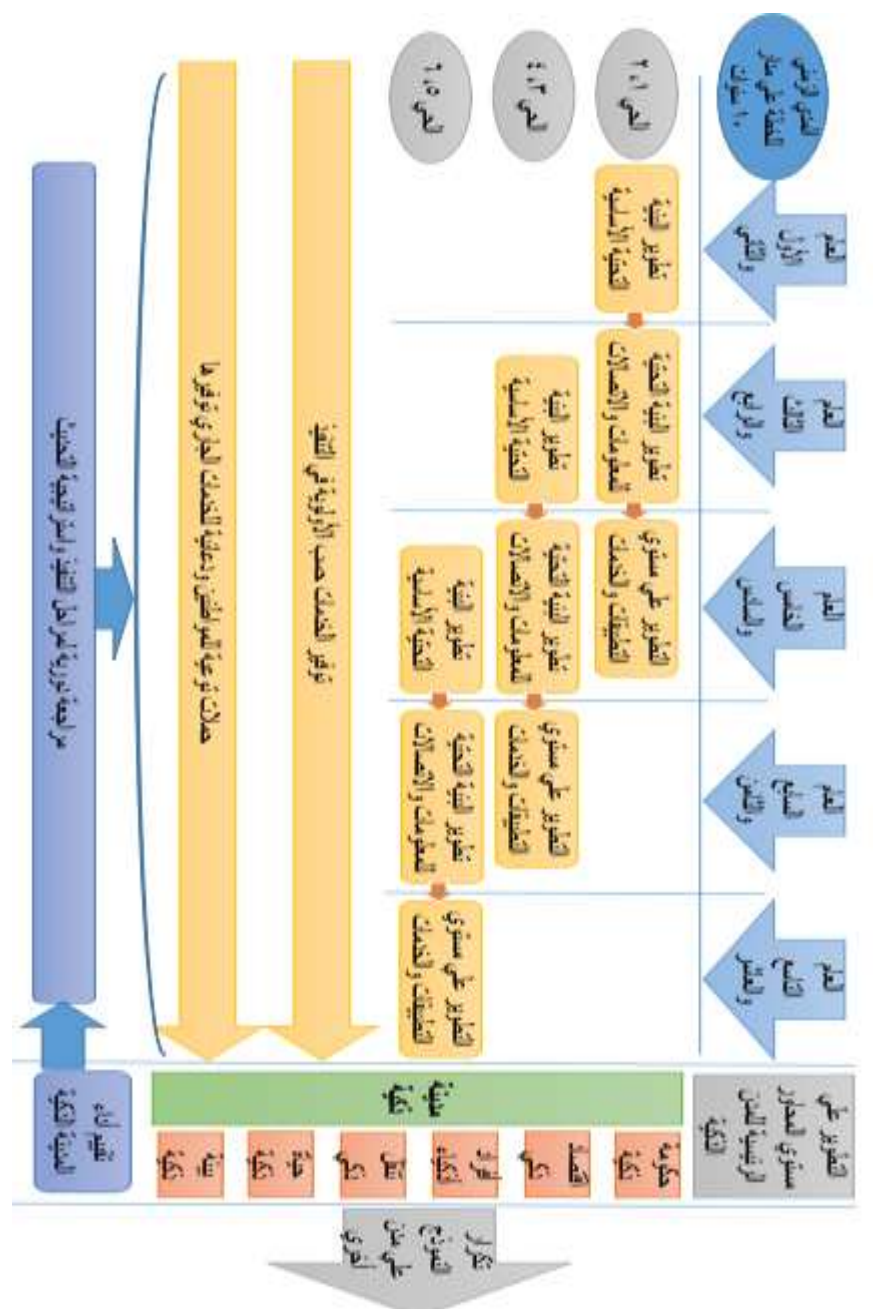

شكل رقم (1 1 ): ديجرام يوضح الخطة الزمنية لتحديث مدينة قائمة إلى مدينة ذكية (بتصرف الباحث) 


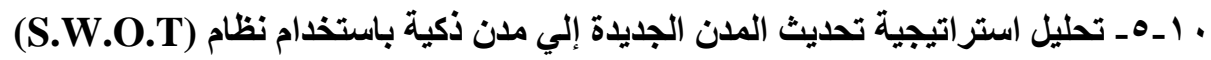
(Strengths, Weaknesses, Opportunities \& Threats) جدول رقم (1): تحليل استراتيجية تحديث الددن الجديدة إلي مدن ذكية باستخدام نظام (S.W.O.T) (بتصرف الباحث)

\begin{tabular}{|c|c|c|c|c|}
\hline التهنيدات والعخاطر (T) & القرص العثاحة (o) & مواطن الضعف (W) & مواطن القوة (s) & \\
\hline 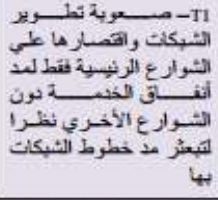 & 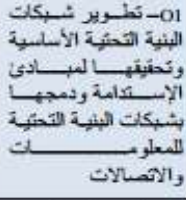 & 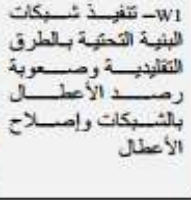 & 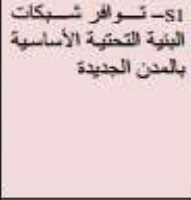 & المديث التينية التحنية \\
\hline 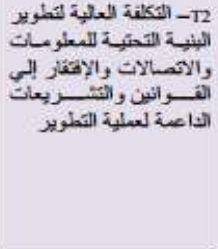 & 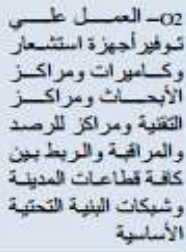 & 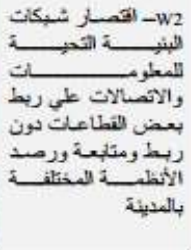 & 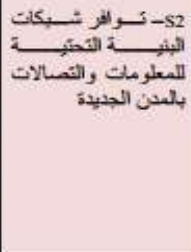 & تحديق التينية \\
\hline 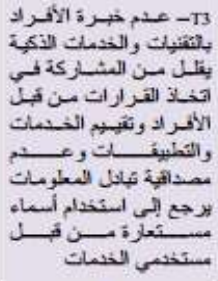 & 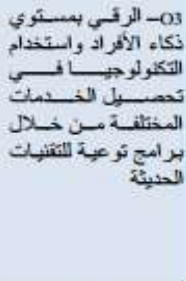 & 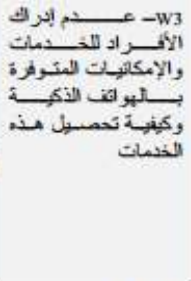 & 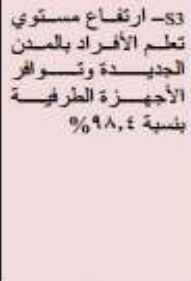 & 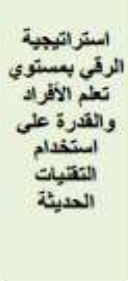 \\
\hline 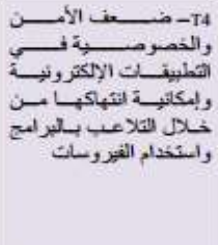 & 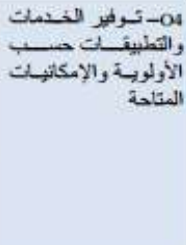 & 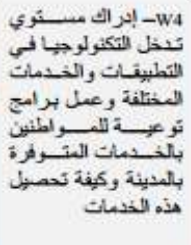 & 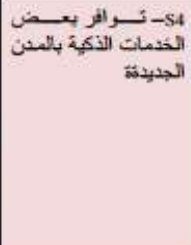 & 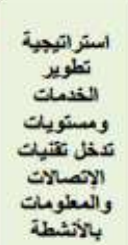 \\
\hline
\end{tabular}

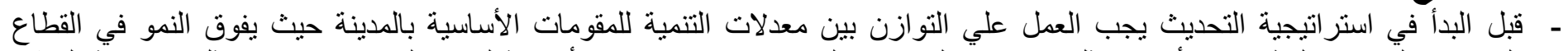
الصناعي النمو في القطاعات الأخري مثل الإسكان و الخدمات بالر غم من كونها عناصر أساسية لجذب السكان كما هو متمثل في مدينة العاثر

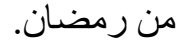

ـ ـ العمل علي رفع معدلات التتمية من خلال تحقيق أهداف المدن علي مستوي الإسكان والخدمات و عدد السكان بالنسبة للعدد المستهدف وزيادة فرص العمل.

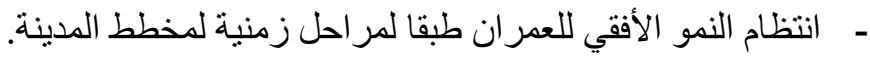

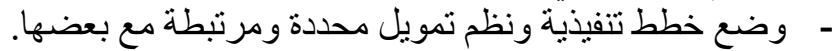

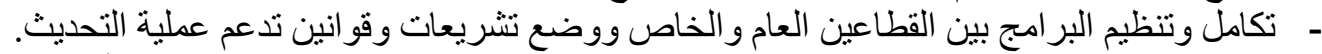

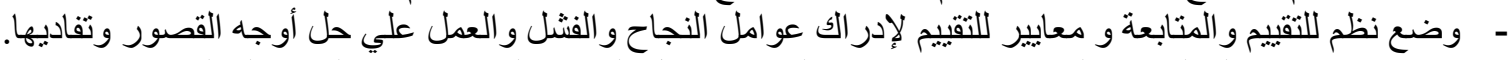

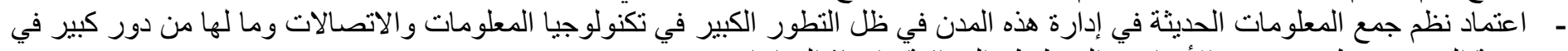

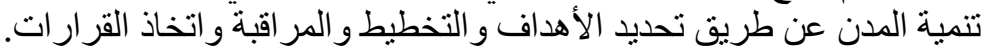

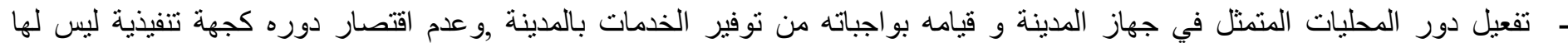

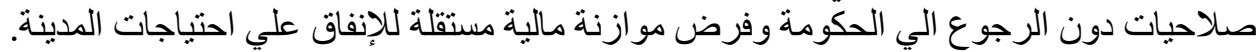

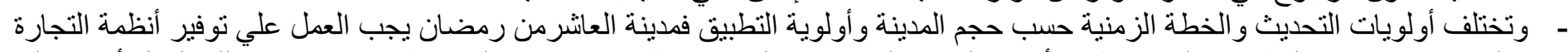

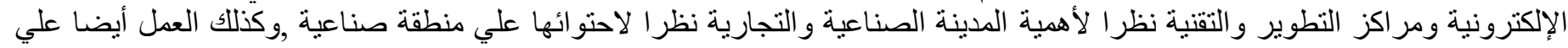
توفير تطبيقات التعليم الإلكتروني و الصحة الإلكترونية و غير ها من التطبيقات الذكية. 


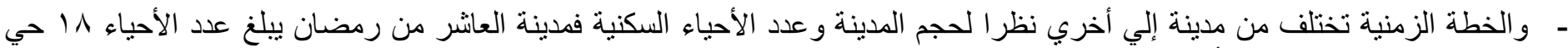

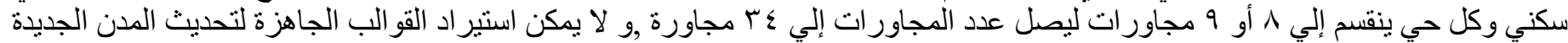

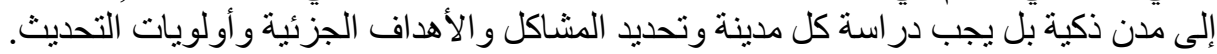

- - مجب علي المخطط إدر الك البعد التكنولوجي الجديد في التصميح. - يجب توفير الخدمات بحيث تشمل سكان المدينة بمختلف الطبقات وذلكئل من خلال توفير وسائل اتصال حديثة وبر امج توعية للاستفادة منها في انشطة الحياة المختلفة

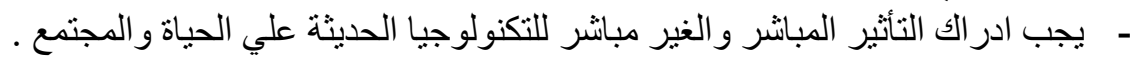

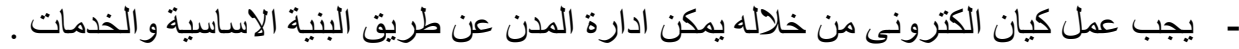

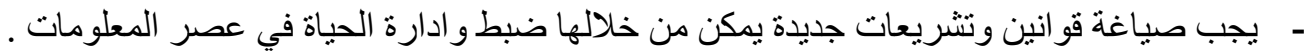

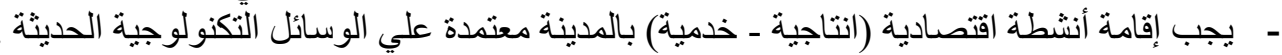

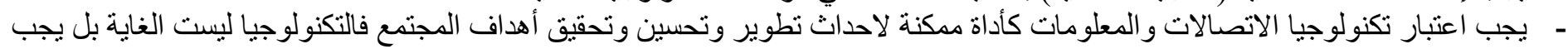

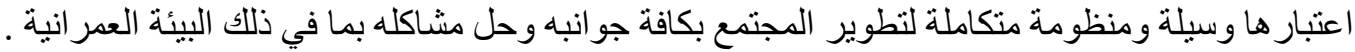

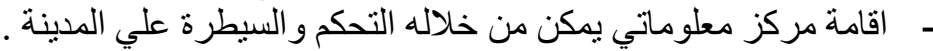

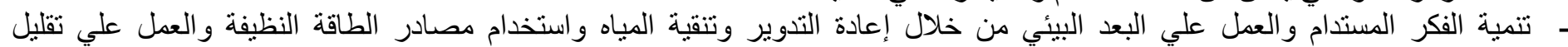
الانبعانات الضارة بالبيئة النئة

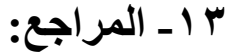

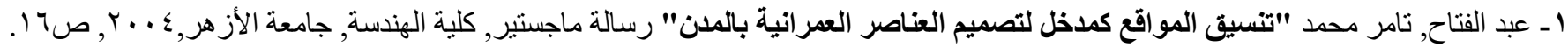
2-California Institute for Smart Communities, “Ten Steps to Becoming a Smart Community”, California/ USA,2011.

http://www.smartcommunities.org/library_10steps.htm, Date Accessed in [13-09-2020]

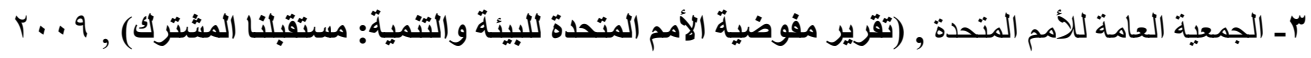

http://www.un-documents.net/wced-ocf.htm Date accessed in [16-09-2020]

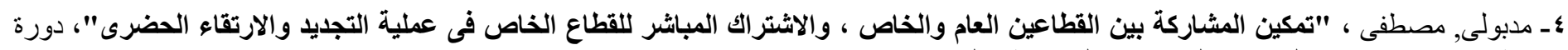

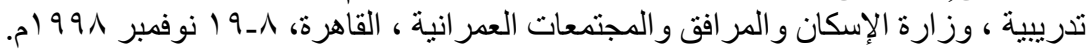

5- https://smartcity.brussels/the-project-definition , Date accessed in [15-10-2020]

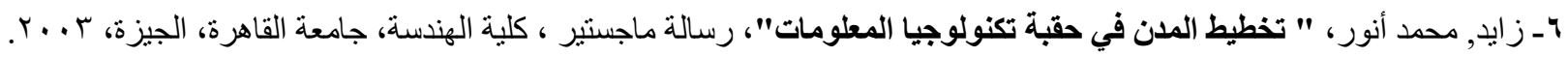

7-Moss M. \& Townsend A., "How telecommunications systems are transforming urban spaces". Cities in the

Telecommunication Age, UK., 2000.

8- Wheeler, J. et al. "Cities in the Telecommunication Age", Routledge, London, 2000.

http://www.informationcity.org/about/modeling.htm , Date Accessed in [21-11-2020]

9 - http://www.informationcity.org. , Date Accessed in [16-12-2020]

$$
\text { (هيئة المجتمعات العمر انبة الجديدة) - } 1 \text { - }
$$

http://www.newcities.gov.eg/know_cities/Tenth_Ramadan/default.aspx, Date Accessed in [29-12-2020]

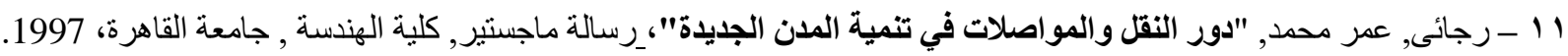

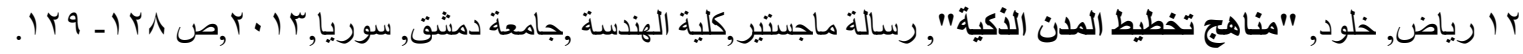

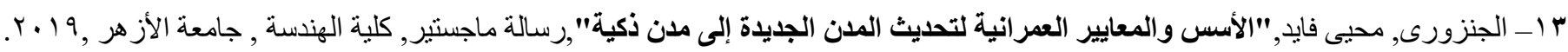

